Article

\title{
Accounting for Cultural Capital-Sustainability Agenda of Charities Serving the First Nations People towards Self-Determination-Evidence from the Northern Territory, Australia
}

Indra Abeysekera (D)

check for updates

Citation: Abeysekera, I. Accounting for Cultural Capital—Sustainability Agenda of Charities Serving the First Nations People towards Self-Determination-Evidence from the Northern Territory, Australia. Sustainability 2022, 14, 949. https:// doi.org/10.3390/su14020949

Academic Editors:

Beatriz Aibar-Guzmán and

Cristina Aibar-Guzmán

Received: 8 December 2021

Accepted: 12 January 2022

Published: 14 January 2022

Publisher's Note: MDPI stays neutral with regard to jurisdictional claims in published maps and institutional affiliations.

Copyright: (C) 2022 by the author. Licensee MDPI, Basel, Switzerland. This article is an open access article distributed under the terms and conditions of the Creative Commons Attribution (CC BY) license (https:// creativecommons.org/licenses/by/ $4.0 /)$.
Discipline of Accounting and Finance, Charles Darwin University, Darwin, NT 0800, Australia; indraabeysekera@gmail.com

\begin{abstract}
This study examined the role of the First Nations beneficiary charities in contributing to the 17 United Nations Sustainable Development Goals (SDGs) in the Northern Territory, Australia, as a way of attaining self-determination by closing the expectations gap between First Nations people and the mainstream Australians. Informed by the theory of self-determination (ethical and functional strands), a latent content analysis of 118 charities serving the First Nations people was conducted, coding the summary of their activities to ascertain their strategic engagement with the SDGs. A network analysis was also carried out to examine the charities' connections with each other and their collective contribution towards the SDGs. The findings show that charities contribute to creating cultural capital through social capital, followed by intellectual capital dimensions. However, charities contributed little to building environmental capital dimension of the First Nations people. This study examined charities' engagement with SDGs to build cultural capital in furtherance of self-determination of Australia's First Nations people.
\end{abstract}

Keywords: Australia; charities; cultural capital; environmental capital; intellectual capital; Northern Territory; self-determination; social capital; sustainability reporting; United Nations Sustainable Development Goals

\section{Introduction}

Australia's First Nations people culture has at least 65,000 years of history; being the oldest civilisation in the world is a reason in itself for this culture to be preserved and nurtured. Figure 1 is a glimpse of the silent witness. It is a culture infused with spirituality and resilience, inseparable in defining identity and belonging; self-determination is an outcome of the culture enjoyed by First Nations people [1]. They derive strength from their culture through collective experiences of adversity that mutually bond them and search for transformative strategies [2].

Among the seven core human rights treaties is the International Covenant on Civil and Political Rights, adopted by the United Nations General Assembly as a multilateral resolution in 1966. The treaty came into force in 1976 under Article 49 of the Covenant. By 2019, 173 parties, including Australia, had ratified the Covenant, with six further signatories [3]. The Covenant contains 53 Articles classified under six parts. Article 1 in Part 1 recognises that all people have the right to self-determination. While there is no universally accepted definition of self-determination [3], the general understanding is that people are entitled to control their destiny and receive respectful treatment in economic, social, and cultural development [4].

The concept of self-determination is central to indigenous communities across the world. Although the United Nations has not defined the term indigenous, proof of direct or indirect association with such ancestry is sufficient for claiming this identity. Seven 
guiding factors relate to identity in indigenous communities [5]: 1. Individuals' and the member group's self-identification with the community. 2. The people were continuing their ancestral existence before colonies or other groups occupied their land. 3 . They are strongly linked to the surrounding natural resources and have a strong affiliation with the land in which they live. 4. They follow social, political, or economic systems that are noticeably different from mainstream thought. 5. They have distinct customs, laws, languages, and beliefs. 6 . They are not the dominant groups in society. 7 . The members of these groups identify themselves to reproduce and maintain their cultural systems and activities conducted as a community.

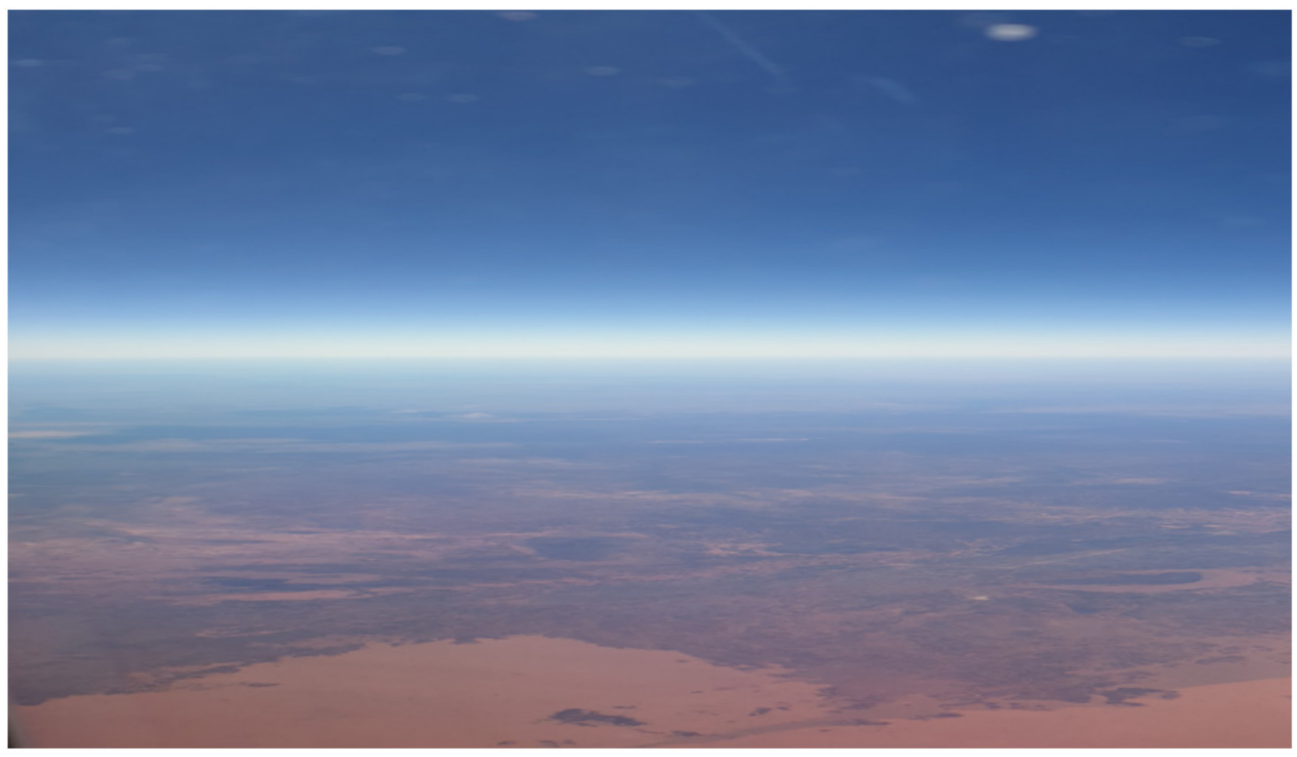

Figure 1. An aerial view of a regional area between Darwin and Alice Springs in the Northern Territory of Australia (photograph taken by the author).

These seven factors have a common theme of descendance from people who inhabited the geographic region before the arrival of other ethnic or cultural groups that later became dominant due to conquest, occupation, settlement, or other means. Over 370 million indigenous people live across 70 countries worldwide. The generic term indigenous has been replaced by other preferred terms across time, such as First Nations, First Peoples, and Aboriginal [5].

The term First Nations people is the contemporary term used to refer to the indigenous population in Australia, which has two distinct cultural groups: Aboriginal and Torres Strait Islander people. The Aboriginal subgroup identifies with a geographic location as custodians of the ecology (including land and water) or with their ancestral spoken languages; Torres Strait Islanders living in Australia identify with the island of their ancestry. In addition to the cultural diversity between these two groups, there is also language diversity with over 250 ancestral spoken languages that they associate with.

The study aims to examine the First Nations beneficiary charities contributing to the 17 United Nations Sustainable Development Goals (SDGs) in Australia's Northern Territory. A foundation of the First Nations people culture is interdependencies among all beings, human and non-human; sustainable development requires taking care of all in a balanced manner. Birth replaces decay, and production restores consumption. The culture also brings knowledge and practices that are local, generational, and intergenerational in nurturing and developing the culture. For instance, First Nations beneficiary charities can share culturally relevant knowledge and practices that are conducive to the culture. Other charities can bring different expertise and practices regarding sustainable development that does not align with First Nations people culture due to differences in the worldviews held and can even diminish the cultural capital in the pursuit of sustainable development. 
Therefore, culture is an important ingredient for sustainable development that aligns with First Nations people's worldview. Sustainable development is the foundation for self-determination to sustain into generations [6].

The First Nations people in Australia represent 798,400 individuals or 3.3 per cent of the Australian population. Ninety-one per cent identify as Aboriginal, five per cent as Torres Strait Islander, and the remaining four per cent as descendants of both cultural groups. The Northern Territory of Australia was chosen for this study because it accommodates 30 per cent of First Nations people, the highest for an Australian territory or state [7]. Although in other states and the Australian Capital Territory, most First Nations people live in urban and regional areas, in the Northern Territory, 81 per cent live in remote areas, and 19 per cent live in regional areas [8]. These areas have the least access to facilities and can correlate with the greatest struggle towards self-determination.

This study examined First Nations people in Australia because as a community group they have experienced numerous chronic disparities compared with the dominant Australian cultural group. These include high child mortality, low school attendance, low levels of literacy and numeracy, low year 12 attainment, low employment, and low life expectancy [9]. Earlier studies have examined interventions by various peoples and institutions, but the role of First Nations people serving charities in accounting for cultural capital towards self-determination is unexplored. The study focuses on the role of charities given the Federal government support for local non-governmental action whereby First Nations people can be empowered with self-determination to make decisions about life choices for themselves and for their future generations.

\section{Relevant Literature}

\subsection{Indigenous Identity and Status}

Various official terminologies are used for the indigenous people in different countries. In Australia, Aboriginal and Torres Strait Islanders are now known as First Nations people. In New Zealand the indigenous community are known as Maori, in the United States as Native Americans, in Canada as First Nations people, and in Norway as Sami people [10].

In Canada and the United States, indigenous people must show registration by descent. In countries such as Australia, New Zealand, Norway, and Sweden, they self-identify as a descendant, and their acceptance by the community they live in or belong to is a sufficient declaration. In terms of demographic profile, Australia, New Zealand, the United States, and Canada have a younger and growing indigenous population, but they also have reported worse socioeconomic indicators compared with the non-indigenous population. In Norway and Sweden, the demographic is an older and declining indigenous population [10].

Canada, New Zealand, and the United States have signed treaties with indigenous peoples, and Norway has state responsibilities for Sami people recognised in the Constitution. Until 1967, Australia referred to indigenous people in the Constitution to exclude them from certain aspects, and in 1967 through a referendum removed them entirely from Constitutional recognition. The absence of constitutional recognition means the current Constitution does not explicitly mention the Aboriginal and Torres Strait Islander people; this also means the Constitution does not recognise indigenous people who previously occupied the land and were the custodians. There are no dedicated parliamentary seats for indigenous people. They also have no guaranteed separate seats in the Commonwealth, State, or Territory level parliaments [11].

In 2019, a survey sampled 1097 respondents, 70 per cent supported the constitutional recognition of indigenous people with 33 per cent flagging it as a priority. The rest supported the change but did not see it as a priority. Twelve per cent were not sure about the constitutional recognition, and 18 per cent did not approve it [12]. 


\subsection{Australian Government Direct Involvement in Indigenous Affairs}

From 1967 to 1972, the Commonwealth government became involved in indigenous affairs in the Northern Territory (NT) and Australian Commonwealth Territory (ACT) following the referendum. After section 51 in the Constitution removed the impediment to making special laws relating to aboriginal affairs, the Commonwealth government played a distant role in the affairs of First Nations people. Although there was a Federal Minister in charge of Aboriginal affairs, there was no separate Commonwealth Department. The Department of the Interior took the primary responsibility to liaise with the Northern Territory about indigenous affairs. The Federal government appointed three non-indigenous men as members of the Council of Aboriginal Affairs who advised on indigenous policy. The government created an Office of Aboriginal Affairs to implement policy [12,13].

From 1972 to 1990, the Commonwealth government had increasing involvement in indigenous affairs. In 1973, the Whitlam government established the Department of Indigenous Affairs which took over the functions of the Council and Office for indigenous affairs established by the previous government [13].

In 1973, the Commonwealth government established the National Aboriginal Consultative Committee, an advisory body comprising indigenous members to advise the government on indigenous affairs. The National Aboriginal Conference later replaced this Council, which had elected all indigenous members. The intention was for them to become the conduit to bring the Aboriginal community's policy plans to the government, but allegations mounted that members representing the National Aboriginal Conference had less than sufficiently connected to represent the Aboriginal communities.

In 1980, to rectify this situation, the government created the Aboriginal Development Commission comprising 10 part-time Aboriginal board members appointed as Commissioners. They managed a limited number of development-oriented indigenous programs. The Commission also administered loans and grants for indigenous housing and indigenous businesses. The government formed several other institutions led by indigenous people to meet various indigenous objectives [13].

As the number of institutional bodies and activities undertaken grew, to bring all activities under one umbrella, in 1989 the Commonwealth government established the Aboriginal and Torres Strait Islander Commission (ATSIC). The ATSIC also replaced the Department of Indigenous Affairs. The ATSIC played an administrative and advisory function to the Parliament governing the First Nations People. In 2005, with the joint support of the government and the opposition, the Parliament abolished the ATSIC. The proponents of the ATSIC stated that this body had less autonomy to make decisions and less funding support. Those opposing the ATSIC pointed to its lack of engagement with the First Nations communities to shape self-determination. The ATSIC closure shifted towards mainstream service delivery determined by the Commonwealth Government rather than First Nations people themselves, who noted the change as a further impediment to selfdetermination [14].

\subsection{Self-Determination and Self-Management}

The self-determination aspect relates to policy formulation, whereas self-management relates to funds management. Self-determination is also associated with human rights and rights to resources. Courts began to recognise indigenous land and resource rights starting in the 1970s in Canada, New Zealand, and the United States. Australia started doing so in the 1990s. Meanwhile, Norway and Sweden do not recognise ownership rights and instead recognise land-use rights [15].

As a salute to self-determination, several countries have made official public apologies for past wrongdoings. In 2002, the New Zealand government offered an apology for administering the nation of Samoa [16], and in 2021 the New Zealand government offered an apology for the discriminatory application of migration law in the 1970s to the Pacific Communities. In 1993, the U.S. Congress adopted a resolution (apology resolution) that acknowledged overthrowing the Kingdom of Hawaii [17]. In 2008, the government in 
Canada made a public apology for removing and isolating First Nations children from their homes, families, and cultures to assimilate them into the dominant culture through a residential school system [18]. In 2008, the government of Australia made a public apology for forcefully removing First Nations children to assimilate them into the dominant culture, acknowledging the pain, suffering, and hurt caused to these First Nations People known as the stolen generation [19]. The Norwegian government has not offered an official apology to the Sami people.

The period 1967 to 1972 was an era when self-determination was not a priority on the Australian government agenda. During that period, non-indigenous people provided advice to the government on indigenous affairs. There was a lack of demonstrated commitment and attention without a dedicated department for indigenous affairs. It was from 1972 that self-determination for First Nations people became an agenda point for discussion. 1972 to 1990 demonstrated a substantial promise and engagement in indigenous affairs with the creation of a separate Department of Indigenous Affairs as well as an Aboriginal member-led advisory council-the National Aboriginal Consultative Committee. The ATSIC also played a similar advisory position.

The First Nations people-led advisory institutions and committees paved the direction towards self-determination, but there was a prominent absence of funds management by First Nations people for their development. Concomitantly, they lack a guaranteed constitutional voice and formal constitutional recognition as the First Nations people on the land.

However, the Mabo judgement recognised indigenous people as the first people in Australia, an alternative to the Crown title called the Native title: to possess, occupy, use, and enjoy the land, in the virtue of preserving laws or customs to those lands [20]. As long as they do so, these lands do not come under Crown land title for lease. Despite legal advancements, the Commonwealth governments have continuously rejected the proposition to offer First Nations people a voice in the Constitution through a referendum. Instead, these governments state that the focus is on the functional areas of improving health, education, and decreasing domestic violence among the First Nations people [9,20]. It is worth noting that the right to self-determination is not about creating a separate state. It is about First Nations people meeting their own social, economic, and cultural needs by making decisions about themselves [21].

The ATSIC, during its operational period, noted that First Nations people in Australia are the most disadvantaged and marginalised group. They experience economic poverty (30 per cent experience income poverty), social poverty (land dispossession), and cultural poverty (cultural values underappreciated by mainstream society such as support to preserve their languages). Although poverty is common among ethnic groups, the First Nations people are the worst off. The First Nations people have reported that marginalisation and disadvantages result from forced circumstances [22].

A key to self-determination is local communities having control over decision-making. Programs launched to support self-determination must be structured to align with selfdetermination goals. For instance, the Northern Territory of Australia Treaty Commission reported little substantive progress made and little alignment regarding programs launched to support self-determination for several years. Alignment is lacking on several fronts. First Nations people have limited housing options offered to them by the respective government department.

Australia's Northern Territory Government has a decision-making program to transfer government services like health, education, and housing to willing First Nations people service providers under the control of local communities. However, the peak First Nations service providers complained that the Territory Government had ignored their comments in drawing up implementation plans [23]. These misalignments have led some community groups to rely less on local government actions. Given that these misalignments have created a vacuum to serve First Nations communities, charities dedicated to serving First 
Nations people can make a solid contribution to advancing local community-based selfdetermination outcomes.

\section{Theoretical Framework}

Charities serving the First Nations people aim to make First Nations people competent and autonomous by relating to others with culturally relevant activities. Inter dependencies are a key intrinsic aspect in the culture that motivates culturally relevant engagements. There are six mini-theories in self-determination. They differ based on how external factors regulate behaviour towards internal factors. The six mini-theories are as follows. 1. Cognitive evaluation theory (external factors influence motivation). 2. Organismic integration theory (rewards specifically influence motivation). 3. Causality orientation theory (orientation influences motivation). 4. Basic psychological needs theory (autonomy, relatedness, and competencies identified as basic needs for motivation). 5. Goals content theory (intrinsic versus extrinsic goals makes a difference to motivation). 6. Relationship motivation theory (relatedness is central to motivation) [24].

This study uses the overarching self-determination theory rather than any specific mini-theory. It best explains the contribution First Nations people charities make by meeting Sustainable Development Goals towards self-determination. According to this theory, people are inherently motivated to internalise important factors even if they are uninteresting. Internalisation occurs when values and processes are not acceptable as their own (introjection). Accepting values and processes as their sense of self (integration) also internalises self-determination [25]. The role of charities that serve First Nations people is to integrate values and processes consistent with the culture, which leads to self-determined engagement. Self-determination theory has three interpersonally supportive dimensionscompetence, relatedness to others, and autonomy. They enable the innate need to satisfy self-determination [26].

Figure 2 provides the theoretical framework of the study. The ethical strand of the self-determination theory states that self-determination is a collective construct located in that community group. It is the individuals in that community, however, who contribute to and create the construct. As much as different societies have different self-determination constructs, the individuals who belong to communities can have their own version of self-determination constructs.

For example, mainstream Australian people subscribe to an individualistic societal self-determination construct, in marked contrast to First Nations people subscribing to a collective societal self-determination construct. Individuals are entitled to understand, appreciate, and enact their versions of self-determination, provided that those variations are acceptable within the group. However, the collective right to self-determination of a community group is associated with individuals having a duty to subscribe to the collective construct. A core meaning of the self-determination construct is not liberalism but decency. Each community group member focuses on personal morality (moral views), and society becomes the collective outcome of ethics (moral codes) [27].

First Nations people comprise community groups associated with more than 250 languages. These contribute to societal and cultural diversity. Variations in customs and local laws may conflict with different communities within the First Nations people due to their own diversities. As a collective community of First Nations people, their moral code may not completely overlap with that of the mainstream Australian people. These variabilities create tensions for accepting and implementing customs and regulations for self-determination decisions in a country. Self-determination, therefore, deals with variations in moral codes. There is no need to have uniformity, but self-determination must fall within an acceptable range so that all communities become differently self-determined but unified in ethical values of making decisions, conducting livelihoods, and obeying laws. 


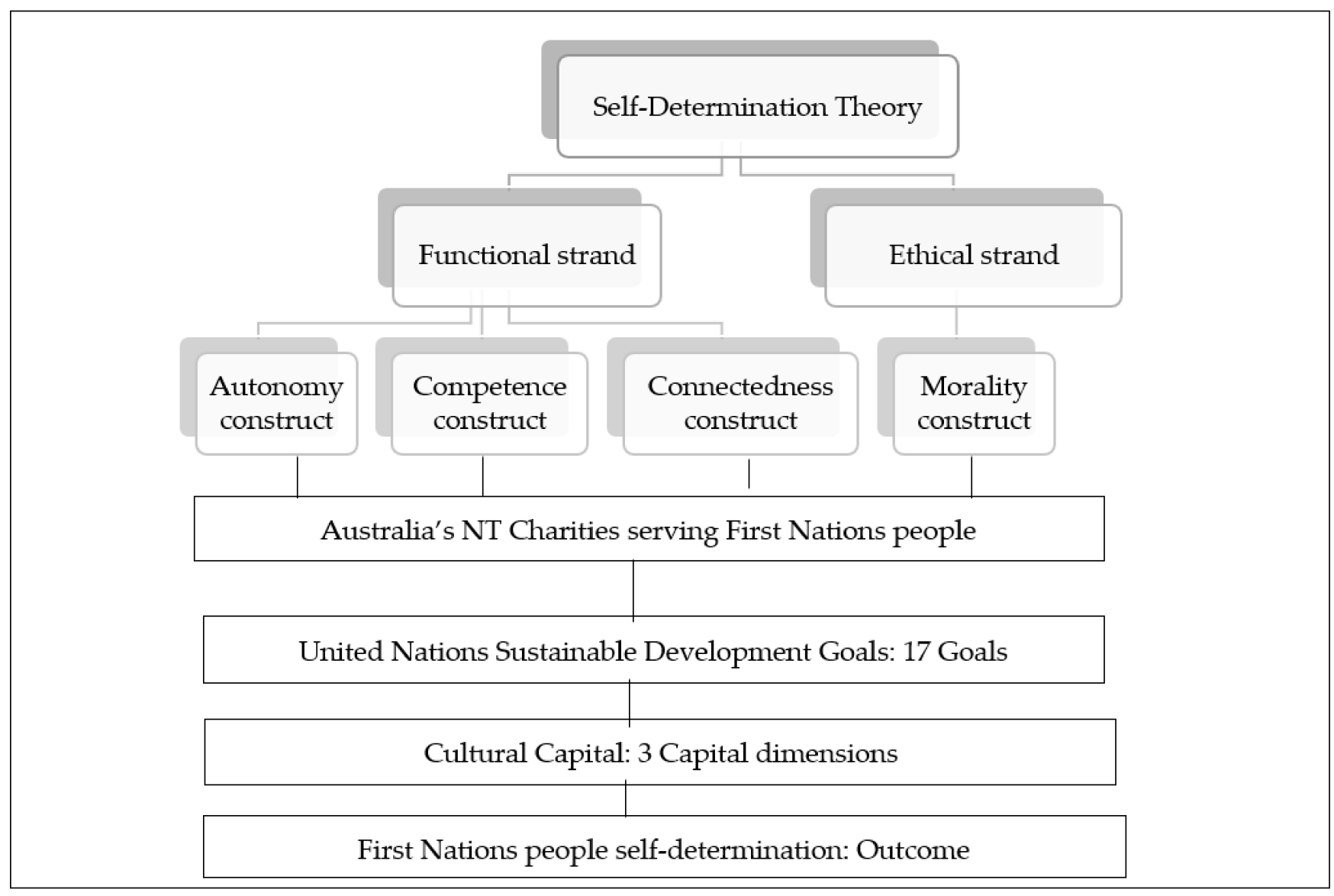

Figure 2. Theoretical framework of the study (compiled by the author).

The processes towards attaining a sufficient threshold of self-determination require transforming individual beliefs into the agreed ethos within the boundaries of Australian sovereignty [28]. These processes must aim to emancipate people from poverty, while preserving their cultural and social heritage in economic, social, and cultural aspects. In May 2017, over 250 First Nations people met at the foot of Uluru to make a unified statement, known as the Uluru Statement. This is a document that all First Nations people agreed upon to state that they are sovereign people and want all Australians to recognise and support this identity. Sovereignty is spiritual to them. Sovereignty is connected to the land their ancestors and they live on because they have owned the soil by occupation. The ultimate goal is to have self-determination included by having a decision-making voice at the Constitutional level $[28,29]$. The self-determination goals must sustain a lasting future for the First Nations people.

The functional strand of the self-determination theory points out three outcomes for the transformed self-determination of people [30]. First, people can make choices and take direct action (autonomy). Second, they have the necessary means to take those actions (competence). Third, they have a relatedness or connectedness with other people to feel they belong to the group (connection or relatedness). The Uluru Statement pointed out that the First Nations people feel powerless, highlighting a lack of autonomy provided to them to make choices about leading their lives [31]. First Nations charities, through their activities, can empower, enable, and connect the First Nations people. The theory also states that there must be autonomous extrinsic motivation for people. Social conditions and social support through social relationships are critical, especially for the First Nations people holding collective societal norms. First Nations charities can actively direct people to acquire skills to become more economically empowered and can appreciate social and cultural values [32-34]. 
Aligning charity activities towards the United Nations Sustainable Development Goals provides a blueprint for peace and prosperity of First Nations people, now and into the future [35]. The functional theoretical strand provides knowledge on general guidelines about common values of sustainable development, while the ways of reaching SDGs can differ considering the specific of indigenous people culture and mentality. Ascertaining charity activities through these goals also aligns with the spiritual connection with the land and essentially the planet [35]. The ethical strand of the theory provides the knowledge that spirituality gives the moral basis for the First Nations people. The charities have a specific objective to serve the First Nations People with culture-specific programs.

Charities facilitate producing and reproducing the First Nations People's distinct culture by embodying, institutionalising, and objectifying them [36]. The embodied culture makes the First Nations People think about land and water spiritually, learn and speak their mother tongue, and socialise with the traditions [36]. The First Nations People works of art and sacred places have objectified the cultural capital. As well as being income generators, they are also consumable without extinction through appreciation, devotion, and enjoyment. The First Nations People can institutionalise them, such as land under the native title, for leasing arrangements to earn royalties. The cultural capital is unique. It is the basis for establishing self-determination of the First Nations People unique to Australia. Based on the above discussions, the research question is as follows: What is the connection between charities that contributes to the First Nations people in the Northern Territory of Australia, as well as the United Nations Sustainable Development Goals (as goals), cultural capital (as output), and self-determination (as outcome)?

\section{Methodology}

In designing the research, to meet its aims, the methodology that sets out ways of collecting data uses the techniques and procedures to analyse data as information. The research design sets the framework for the analysis [37].

\subsection{Data}

The study identified charities that contribute to the First Nations people from the publicly available database, selecting charities that have an address in the Northern Territory with the primary beneficiary as Aboriginal and Torres Strait Islander people. There were 118 such charities published for the year 2019.

\subsection{Research Methods}

The summary of activities of each charity was analysed using latent content analysis. The summary of activities states the strategic actions that charities undertake to fulfil their mission by focusing on what most matters to the charities and their beneficiaries. The textual content is a valuable data source to appreciate charities' contributions. The latent content analysis technique allows the hidden meanings in these texts to be uncovered [38,39].

The coding framework was the 17 United Nations Sustainable Development Goals (SDGs). The meanings embedded in the 17 SDGs in the summary of activities were assessed. In instances where the content analysed included more than one goal, all of them were included in the study as data for analysis [40].

A challenge in latent content analysis is to overcome subjectivity in the data extraction using the coding framework. The two aspects of concern are validity and reliability, terms used in quantitative research. The terms validity and reliability relate to trustworthiness in qualitative research, which means credible, transferable, dependable, and able to be confirmed [41].

In this research, it was ensured that coded data were trustworthy by using an established framework for coding - the 17 United Nations SDGs. The study also used the operational definitions provided for the goals by that framework. These steps eliminated 
subjective researcher interventions and satisfactorily addressed the issue of comparable quantitative validity.

Reliability refers to the coding accuracy established in one of two ways, simultaneously or sequentially. The same coder can carry out the coding using the sequential approach after a time interval that eliminates the need for the researcher to carry the pre-registered memory from the first data extraction into the second data extraction. Both approaches can code the content to obtain coded data and compare them as a quantitative percentage of agreement, providing reliability. Another way is to mimic statistical significance as a measure of agreement-alpha, kappa, and pi; the significance level is adjusted based on researcher judgment [42]. The difference between the two approaches is that two or more coders can carry out the coding in a simultaneous approach.

The most damaging error in coding arises when the coder is lacking necessary research expertise. In this study, it was ensured that the coder had decades of content analysis coding experience with similar coding studies. The coder performed the initial coding and reviewed it using the sequential approach a fortnight later and found a very high degree of agreement. In cases of doubt, another experienced researcher acted as a third party. This approach is established in published research and satisfactorily addresses the comparable quantitative reliability aspect [43].

The purpose of coding text as data was to identify whether the content in the summary of activities informs the SDGs. If the SDGs are present then the content is assigned the number 1, otherwise zero, for each goal identified from the analysed content.

As advised by the ethics branch of self-determination theory, the collective mission of First Nations beneficiary charities is to build a moral code of self-determination. The functional aspect of self-determination theory is to uplift the First Nations people from poverty by building social capital, environmental capital, and non-economic intellectual capital. On that basis, this study clustered the 17 SDGs accordingly to gain a sharper appreciation of the charity's contribution to these forms of capital as follows.

I There are four goals related to intellectual capital:

(1) Goal 9-Industry, innovation and infrastructure;

(2) Goal 11-Sustainable cities and communities;

(3) Goal 12-Responsible consumption and production;

(4) Goal 17-Partnership for the goals.

II There are five goals related to environmental capital:

(1) Goal 6-Clean water and sanitation;

(2) Goal 7-Affordable and clean energy;

(3) Goal 13-Climate action;

(4) Goal 14-Life below water;

(5) Goal 15-Life on land.

III There are eight goals related to social capital:

(1) Goal 1-No poverty;

(2) Goal 2-Zero hunger;

(3) Goal 3-Good health and wellbeing;

(4) Goal 4-Quality education;

(5) Goal 5-Gender equality;

(6) Goal 8-Decent work and economic growth;

(7) Goal 10-Reduced inequalities;

(8) Goal 16-Peace, justice and strong institutions.

Each charity's engagement with a United Nations SDG earned a score of 1 or 0 (binary count) aggregated to receive a score for intellectual capital, environmental capital, and social capital. The next step analysed these extracted data to ascertain the collective position of the 118 charities using the network analysis research method using Gephi 0.9.2 software [44]. The research recorded the data for the 118 charities in Microsoft Excel. The 118 charities are the nodes or the actors, and the capital dimensions (intellectual capital, environmental 
capital, social capital) are the edges or connectors of these actors. The visualisation of actors (charities) with connectors (sustainable goal dimensions) allows us to appreciate capital creation contribution to alleviate First Nations people's multi-dimensional poverty by building their broad capital base.

\section{Findings}

Table 1 shows that 118 charities serving the First Nations people actively build the capital bases. Since some charities engage with more than one SDG, the total is 231 and not 118 .

Table 1. Sustainable Development Goals collectively served by First Nations charities in the Northern Territory (compiled by the author).

\begin{tabular}{cc}
\hline Cultural Capital Dimension & Number of Firm Goals Served \\
\hline Intellectual capital & 66 \\
Environmental capital & 13 \\
Social capital & 152 \\
Total & 231 \\
\hline
\end{tabular}

The primary capital dimension these charities create is social capital, with 152 firm goals. Charities collectively and evenly contribute to all socially Sustainable Development Goals, but only one charity was identified as contributing to gender equality social capital development. The most engaged social development goal is reducing inequalities. The second least involved development social development goal is the reducing the hunger development goal.

There are eight goals related to social capital, and the distribution of charity involvement is as follows.

(1) Goal 1-No poverty = 20;

(2) Goal 2-Zero hunger = 0;

(3) Goal 3-Good health and wellbeing = 28;

(4) Goal 4-Quality education = 20;

(5) Goal 5-Gender equality = 1;

(6) Goal 8-Decent work and economic growth = 21;

(7) Goal 10-Reduced inequalities = 29;

(8) Goal 16-Peace, justice and strong institutions $=24$.

The intellectual capital base dimension findings showed that the most engaged goal is building smart cities and communities. There was no charity involved in contributing to responsible consumption. Charities are also engaged in building infrastructure, industry, and innovation.

There are four goals related to intellectual capital, and the distribution of charity involvement is as follows.

(1) Goal 9-Industry, innovation and infrastructure $=19$;

(2) Goal 11-Sustainable cities and communities = 35;

(3) Goal 12-Responsible consumption and production = 0;

(4) Goal 17-Partnership for the goals $=12$.

The environmental capital base building received the least attention. Collectively among charities, life on land received the most engaged attention, whereas there was no charity engaged in the affordable clean energy goal.

There are five goals related to environmental capital, and the distribution of charity involvement is as follows.

(1) Goal 6-Clean water and sanitation =1;

(2) Goal 7-Affordable and clean energy =0;

(3) Goal 13-Climate action $=1$; 
(4) Goal 14-Life below water = 3;

(5) Goal 15-Life on land $=8$.

Figure 3 visualises the 118 charities engaged in Sustainable Development Goals. The visual diagram shows a constellation of charities serving social capital development goals. For example, the first charity in this sample contributes to two goals for intellectual capital, one goal for environmental capital, and three goals for social capital. Each SDG is different. In the first charity, three goals social capital cluster closely, but there are distances because they are other goals. However, social capital is the densest cluster for the first charity, followed by intellectual capital, and the least is environmental capital. Gephi was used to analyse and visually plot all 118 charities.

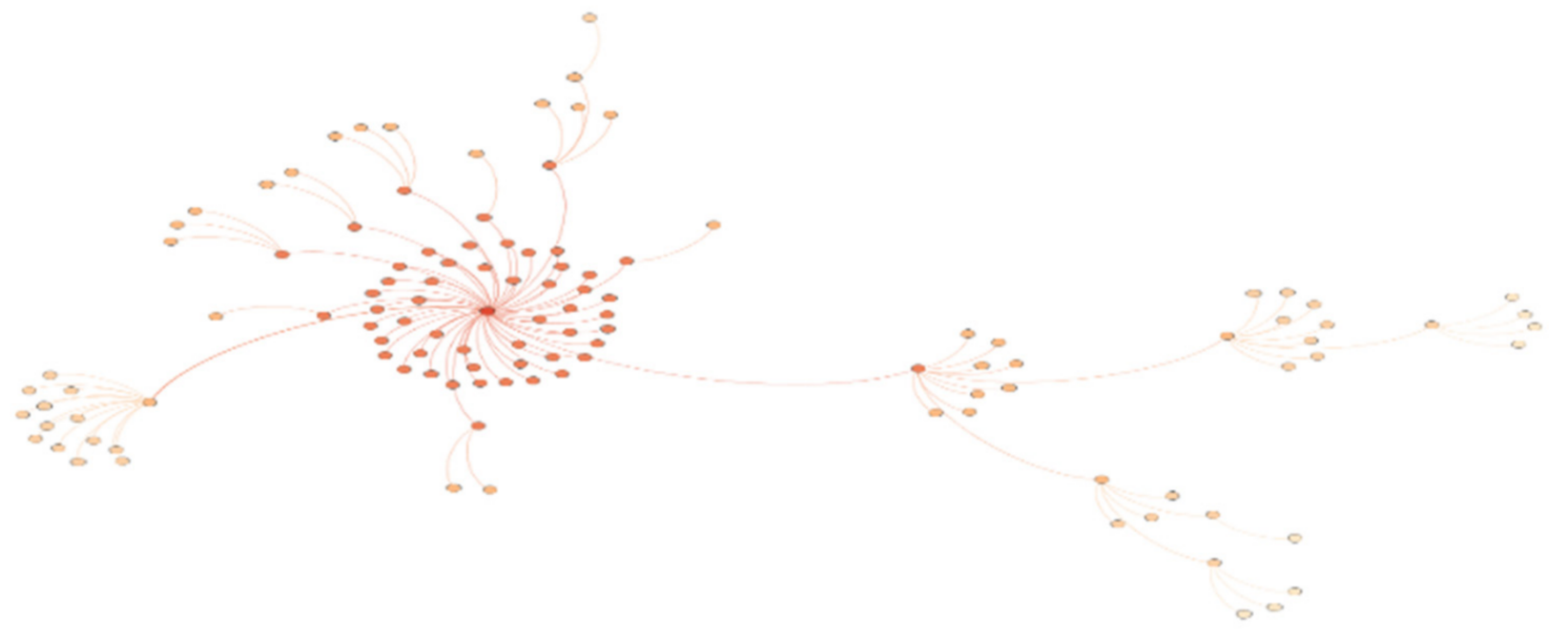

Figure 3. Visualisation of charities engaged in building cultural capital (compiled by the author).

Figure 3 obtained from Gephi output shows a heavy clustering of charities (actors) towards the left side of the chart. As evident from Table 1, these charities are primarily engaged in building cultural capital the social capital base. On many occasions, more than one charity engages with a given sustainability goal and more so with sustainability goals representing social capital. The remaining clusters are weak and spread out. They relate to charities engaging with building environmental capital and intellectual capital.

Table 2 shows the network analysis statistics of cultural capital. The average degree of 1.98 indicates that a charity serves two Sustainable Development Goals on a mathematical average. The weighted average degree 2 means charity contributes to two Sustainable Development Goals. The visualisation diagram generated a web of 118 charities (nodes) serving SDGs (edges). The network diameter of 4 shows that serving four SDGs is prioritized by a few charities. A graph density of 0.017 indicates that charities currently contribute to SDGs at less than their full potential. Although this possibility exists, other factors such as charities' funding can constrain them. The modularity is less than 1 with 0.3 , showing that charities serve different goals in the same capital dimension. For instance, a charity that operates in the social capital dimension tends to concentrate on SDGs in that capital dimension but less so in other capital dimensions. The connected component is 1 , meaning each charity serves at least one SDG. The average clustering coefficient of 0 indicates that charities are not connected but focus on their own activities. However, these reported results could be because this study has not included any interconnections among charities for analysis. The eigenvector centrality is 0.005 , showing that no one charity has a noticeable influence on the network of charities. The average path length of 2.769 is the mathematically computed minimum value for SDGs served by a randomly chosen charity in the sample. 
Table 2. Network analysis statistics of building cultural capital (compiled by the author).

\begin{tabular}{cc}
\hline & Cultural Capital \\
\hline Average degree & 1.983 \\
Average weighted degree & 2 \\
Network diameter & 4 \\
Graph density & 0.017 \\
Modularity & 0.3 \\
Connected components & 1 \\
Average clustering coefficient & 0 \\
Eigenvector centrality & 0.005 \\
Average path length & 2.769 \\
\hline
\end{tabular}

\section{Final Remarks}

Charities in the Northern Territory serving the First Nations people play an essential role in creating self-determination. They primarily create the social capital base to reduce inequality and increase good health and wellbeing. These constitute the most engaged SDGs in the social capital dimension. The Uluru Statement declared that the structural systems had created unfairness and disadvantage, and these charity engagements to serve the First Nations people in the Northern Territory of Australia attempt to mitigate these disparities [45].

There are three phases for self-determination to actualise: restoring past injustices, eliminating current and future inequities, and building on justice. In 2008, the Commonwealth government made a public apology to the First Nations people, emphasising the Stolen Generation when children were forcefully removed from their families and homes. The intention was to acknowledge the right to make choices regarding living towards self-determination but still less travel road towards self-determination [46]. The apology assisted in rebuilding First Nations people's social capital.

First Nations people must continue building and protecting their economic, social, environmental, and intellectual capital. Aboriginal communities have a closer connection to the land, and Torres Strait Islanders have a more intimate relationship to the water. Torres Strait Islander representation in the Northern Territory is 1.3 per cent, and those identifying as Aboriginal or Torres Strait Islander number 2.9 per cent. The average rainfall in the Northern Territory is 371 millimetres a year, the second lowest of any state or territory in Australia, and below the average annual rainfall of 483.4 millimetres a year in Australia [47]. Charities' activities tend to display very little focus on building local environmental capital. The limited water availability in the Northern Territory is a possible antecedent for charities to have less engagement.

Implications for Northern Territory charities serving First Nations people: In 2005, Indigenous and Torres Strait Islander Commissioner in the Social Justice Report, urged governments at all levels to promote equality in health and life expectancy within 25 years. In 2007, the Council of Australian Governments (COAG, state and territory governments) pledged to close the gaps between First Nations people and mainstream Australians. In 2008, the Commowealth government and the COAG approved the National Indigenous Reforms Agreement with six targets: 1. Close the life expectancy gap within a generation. 2. Halve the First Nations children under-five mortality rate within a decade. 3. Provide early childhood education for all First Nations four-year-olds in remote communities within five years. 4. Halve the gap in reading, writing and numeracy achievements for children within a decade. 5 . Halve the gap for Indigenous students in year 12 attainment rates by 2020. 6. Halve the gap in employment outcomes between Indigenous and non-Indigenous Australians within a decade. The Commonwealth government also supported several First Nations people-specific partnerships, including Closing the Gap in the Northern Territory National Partnership Agreement [48].

Recent reporting on these targets shows although the targets were not achieved, progress is being made. However, the overall life expectancy gap and meeting the academic 
achievement gap are less than satisfactory. The employment gap is widening. The study findings show that 21 charities have engaged in creating decent work and economic growth, and the Close the Gap Report calls for greater engagement. The study found 20 charities involved in providing quality education, and a greater engagement would be a beneficial move to Closing the Gap.

Policy implications: The 2020 Closing the Gap Report states that decision-making in closing the gap between mainstream Australians and First Nations people is the responsibility of governments at all levels. The government has made a commitment to not invest in mainstream organisations at the expense of community-controlled sectors and to separate wherever possible reporting targets as stolen generation survivors, people with disabilities, and LGBTQI (Lesbian, Gay, Bisexual, Transgender, Queer or Questioning, and Intersex) communities to ensure that the most vulnerable groups are taken care of. The findings assist in refining funding disbursement, funding targets, and levels of government to work on attaining self-determination as promptly as possible [48].

The First Nations people's barrier to getting elected to the Commonwealth Parliament is their low and dispersed population. A future negotiated model like New Zealand's guaranteed parliamentary representation from areas with a high concentration of First Nations people can become an interim solution to the Uluru Statement objective of having a law-making voice. Although there is an opposing view that providing an advantage is discriminatory in favour of the First Nations people, this is intended as a compensatory mechanism for the most adversely affected minority experiencing disadvantages due to their disproportionate poverty level. It is unlikely that the willing mainstream population supporting the First Nations people's expectation gap will vote on these issues in democratic elections, given that elections make people behave selfishly to resolve their issues through lawmakers.

The results report no charity serving First Nations people on responsible consumption. It is an aspect that requires direct and conscious policy intervention towards selfdetermination. Although tobacco smoking, illicit drugs, and alcohol consumption have reduced over the years in Australia, it remains disproportionately high among young adult First Nations people [49]. In translating the Sustainable Development Goals in general, the constructed policies and processes must align with the worldview of First Nations people culture because they become the foundations to create indicators. Otherwise, the indicators may not account for the cultural capital or promote self-determination $[49,50]$.

Over the past decade, the Productivity Commission indigenous expenditure reports have shown that total Commonwealth, State, and Territory government per capita expenditure on First Nations people is double that of other Australians. In 2015-2016, direct spending for a First Nations person was AUD 44,886, and this figure was AUD 22,356 for other Australians. The main driver for these expenditures is not First Nations peoplespecific programs but higher government programs. The First Nations people-specific services accounted for 18 per cent in 2015-2016, a drop from 22.5 per cent in 2008-2009. First Nations people are demographically younger and have more children along with a higher fertility rate. These lead to more demands on childcare, pre-school, school, vocational, and higher education services. Additionally, the higher level of hardship leads to more resources in hospitals, prisons, social security, and social housing. The disadvantages also lead to the use of resources to divert people from socially undesirable outcomes [51].

Theoretical implications: The ethical branch of self-determination theory highlights the essential moral variations in advancing self-determination, within a range acceptable to the law. The findings show that the charities do not engage with gender inequality in the Northern Territory among the First Nations people. The First Nations adults have a 32 per cent higher chance of being hospitalised due to family violence [50,51]. These national statistics are crucial indicators for more charity engagement to increase gender equality and research and interventions to reach lawful solutions. Additionally, the charity engagement shows more social capital development but less intellectual capital development among First Nations people. The functional branch of self-development theory 
highlights the importance of capacity building to sustain decision-making choices and lead decent lives. Twenty charities are currently engaged in quality education as a goal, but more charities engaging in quality education would facilitate greater capacity building required for self-determination.

Research limitations: Conducting latent content analysis required judging the meaning of content embedded in the summary of activities statement in charities and relating this meaning to the pre-defined sustainability goals in the United Nations SDG framework. The researcher had the necessary expertise and experience to make a sound judgement. Still, there is an element of subjectivity that can translate into error. A single-year analysis provides a snapshot of findings, and this study does not offer a trend analysis. Over the years, the composition of Northern Territory charities and their activities can change.

Future research: The results do not explain why Northern Territory charities heavily focus on social capital creation for the First Nations people. The study also does not explain various factors that may have facilitated or hindered charity activities. These factors can include the availability of volunteers, charity constitution, government funding constraints, donor contributions, funding raised by the charity through donations and through commercial activities, and those who governed the charity. Researching the extent of capability building of First Nations people is core to self-determination and must become an ongoing research project.

Funding: This research received no external funding.

Institutional Review Board Statement: Not applicable.

Informed Consent Statement: Not applicable.

Data Availability Statement: The study used publicly available secondary data.

Conflicts of Interest: The author declares no conflict of interest.

\section{References}

1. Dew, A.; Barton, R.; Gilroy, J.; Ryall, L.; Lincoln, M.; Jensen, H.; Flood, V.; Taylor, K.; McCrae, K. Importance of Land, family and culture for a good life: Remote Aboriginal people with disability and carers. Aust. J. Soc. Issues 2019, 55, 418-438. [CrossRef]

2. Usher, K.; Jackson, D.; Walker, R.; Durkin, J.; Smallwood, R.; Robinson, M.; Sampson, U.N.; Adams, I.; Porter, C.; Marriott, R. Indigenous Resilience in Australia: A Scoping Review Using a Reflective Decolonizing Collective Dialogue. Front. Public Health 2021, 9, 162. Available online: https://www.frontiersin.org/articles/10.3389/fpubh.2021.630601/full (accessed on 11 January 2022). [CrossRef] [PubMed]

3. Australian Institute of Aboriginal and Torres Strait Islander People (AIATSIS). Indigenous Australians: Aboriginal and Torres Strait Islander People. Available online: https:/ / aiatsis.gov.au/explore/indigenous-australians-aboriginal-and-torres-straitislander-people (accessed on 28 November 2021).

4. United Nations Human Rights, Office of the High Commissioner. International Covenant on Civil and Political Rights. 2021. Available online: https:/ / www.ohchr.org/en/professionalinterest/pages/ccpr.aspx (accessed on 27 November 2021).

5. United Nations Permanent Forum of the Indigenous Issues. Who Are Indigenous People? Factsheet. 2021. Available online: https:/ / www.un.org/esa/socdev/unpfii/documents/5session_factsheet1.pdf (accessed on 28 November 2021).

6. Watene, K.; Yap, M. Culture and sustainable development: Indigenous contributions. J. Glob. Ethics 2015, 11, 51-55. [CrossRef]

7. Australian Bureau of Statistics. Estimates of Aboriginal and Torres Strait Islander Australians. 2016. Available online: https:/ / www.abs.gov.au/statistics/people/aboriginal-and-torres-strait-islander-peoples/estimates-aboriginal-and-torresstrait-islander-australians/latest-release (accessed on 28 November 2021).

8. Korff, J. Aboriginal Population in Australia. 24 April 2021. Available online: https://www.creativespirits.info/aboriginalculture/ people/aboriginal-population-in-australia (accessed on 17 September 2021).

9. Australian Government. Closing the Gap Report. 2020. Available online: https://ctgreport.niaa.gov.au/sites/default/files/pdf/ closing-the-gap-report-2020.pdf (accessed on 28 November 2021).

10. Social Policy Group. Indigenous Affairs in Australia, New Zealand, Canada, United States of America, Norway and Sweden. Background Paper 15 1997-98. Parliament of Australia. 1998. Available online: https://www.aph.gov.au/About_Parliament/ Parliamentary_Departments/Parliamentary_Library/Publications_Archive/Background_Papers/bp9798/98Bp15 (accessed on 3 December 2021).

11. Mindem, H. Indigenous People: Self-Determination, Knowledge and Indigeneity; Eburon Academic Publishers: Delft, The Netherlands, 2008. Available online: https:/ / www.worldcat.org/title/indigenous-peoples-self-determination-knowledge-indigeneity/oclc/ 759825384 (accessed on 10 January 2022). 
12. Murphy, K. Essential Poll: Majority of Australians Want Indigenous Recognition and Voice to Parliament. 2 July 2019. Available online: https: / / www.theguardian.com/australia-news/2019jul/12/essential-poll-majority-of-australians-want-indigenousrecognition-and-voice-to-parliament (accessed on 10 January 2022).

13. Pratt, A.; Bennett, S. Current Issues Brief No. 4 2004-05. The End of ATSIC and the Future Administration of Indigenous Affairs. Parliament of Australia. 2004. Available online: https://www.aph.gov.au/About_Parliament/Parliamentary_Departments/ Parliamentary_Library/Publications_Archive/CIB/Current_Issues_Briefs_2004_-_2005/05cib04 (accessed on 3 December 2021).

14. Aboriginal and Torres Strait Islander Social Justice Commissioner; Social Justice Report; Report Number 3/2005; Indigenous Law Centre, Law School, University of New South Wales: Sydney Australia, 2006. Available online: https://humanrights.gov.au/ sites/default/files/content/social_justice/sj_report/sjreport05/pdf/SocialJustice2005.pdf (accessed on 5 December 2021).

15. Anae, N. Apia, Our Story. New Zealand's Place is in the Pacific. 2002. Available online: https://www.mfat.govt.nz/en/aboutus/mfat75/75-our-story/apia/ (accessed on 3 December 2021).

16. Arden, R.H.J. Speech to Dawn Raids Apology. 1 August 2021. Available online: https://www.beehive.govt.nz/speech/speechdawn-raids-apology (accessed on 3 December 2021).

17. United States Public Law 103-150. The "Apology Resolution". Passed by Congress and Signed by President William J. Clinton on 23 November 1993. Available online: https:/ / www.hawaii-nation.org/publawsum.html (accessed on 3 December 2021).

18. Government of Canada. Statement of Apology to Former Students of Indian Residential Schools. Prime Minister Harper Offers Full Apology on Behalf of Canadians for the Indian Residential Schools System. Ottawa, Ontario. 2008. Available online: https:/ / www.rcaanc-cirnac.gc.ca/eng/1100100015644/1571589171655 (accessed on 3 December 2021).

19. Parliament of Australia. Apology to Australia's Indigenous Peoples. 2008. Available online: https://www.aph.gov.au/Visit Parliament/Art/Exhibitions/Custom_Media/Apology_to_Australias_Indigenous_Peoples (accessed on 3 December 2021).

20. High Court of Australia. Mabo v Queensland (No 2) ("Mabo case") [1992] HCA 23; (1992) 175 CLR 1 (3 June 1992 ), Mabo and Others v. Queensland (No. 2) [1992] HCA 23; (1992) 175 CLR 1, F.C. 92/014. Available online: http:/ /www6.austlii.edu.au/cgibin/viewdoc/au/cases/cth/HCA/1992/23.html (accessed on 3 December 2021).

21. Parliament of Australia. Chapter 13_Indigenous Australians. 2021. Available online: https://www.aph.gov.au/parliamentary_ business/committees/senate/community_affairs/completed_inquiries/2002-04/poverty/report/c13 (accessed on 4 December 2021).

22. Australian Human Rights Commission. Right to Self Determination. 2021. Available online: https://humanrights.gov.au/ourwork/rights-and-freedoms/right-self-determination (accessed on 4 December 2021).

23. Altman, J. Lest We Forget: The Harmful Policy Legacies of the Northern Territory Intervention. Arena, 24 June 2021. Available online: https:/ / arena.org.au/lest-we-forget-the-harmful-policy-legacies-of-the-northern-territory-intervention/ (accessed on 11 January 2022).

24. Deci, E.L.; Ryan, R.M. Self-determination theory. In Handbook of Theories of Social Psychology; Van Lange, P.A.M., Kruglanski, A.W., Higgins, E.T., Eds.; Sage Publications Ltd.: Thousand Oaks, CA, USA, 2012; pp. 416-436. Available online: https: / / psycnet.apa.org/record/2011-21800-020 (accessed on 11 January 2022). [CrossRef]

25. Deci, E.L.; Eghrari, H.; Patrick, B.C.; Leone, D.R. Facilitating Internalization: The Self-Determination Theory Perspective. J. Peraonality 1994, 62, 119-142. [CrossRef] [PubMed]

26. Ryan, R.M.; Deci, E.L. Self-determination theory and the facilitation of intrinsic motivation, social development, and well-being Am. Psychol. 2000, 55, 68-78. Available online: https://uvi.edu/files/documents/College_of_Liberal_Arts_and_Social_Sciences/ social_sciences/OSDCD/National_Self_Determination_Richard_Ryan_and_Edward_Deci.pdf (accessed on 10 January 2022). [CrossRef] [PubMed]

27. Van der Vossen, B. Self-Determination and Moral Variation: The Theory of Self-Determination; Tesón, F.R., Ed.; Cambridge University Press: Cambridge, UK, 2016; pp. 13-31. [CrossRef]

28. McKay, D. Uluru Statement: A Quick Guide. 19 June 2017. Available online: https://www.aph.gov.au/About_ Parliament/Parliamentary_Departments/Parliamentary_Library/pubs/rp/rp1617/Quick_Guides/UluruStatement (accessed on 4 December 2021).

29. Deci, E.L.; Ryan, R.M. Conceptualizations of intrinsic motivation and self-determination. In Intrinsic Motivation and SelfDetermination in Human Behavior. Perspectives in Social Psychology; Springer: Boston, MA, USA, 1985. [CrossRef]

30. Ryan, R.M.; Deci, E.L. Intrinsic and extrinsic motivation from a self-determination theory perspective: Definitions, theory, practices, and future directions. Contemp. Educ. Psychol. 2020, 61, 101860. [CrossRef]

31. The Uluru Statement. The Uluru Statement from the Heart. 2007. Available online: https://ulurustatement.org/the-statement (accessed on 4 December 2021).

32. Cherry, K. Self-Determination Theory and Motivation. 15 March 2021. Available online: https://www.verywellmind.com/whatis-self-determination-theory-2795387 (accessed on 29 November 2021).

33. Thompson, J. Indigenous Organisations Question Progress on N.T. Government's Self-Determination Program. 15 September 2021. Available online: https://www.abc.net.au/news/2021-09-15/local-decision-making-program-indigenous-nt-governmentcriticism/100460442 (accessed on 4 December 2021).

34. SCRGSP (Steering Committee for the Review of Government Service Provision). 2017 Indigenous Expenditure Report, Productivity Commission, Canberra. Commonwealth of Australia. 2017. Available online: https://www.pc.gov.au/research/ongoing/ indigenous-expenditure-report/2017/ier-2017-indigenous-expenditure-report.pdf (accessed on 11 January 2022). 
35. United Nations. 17 Goals. Department of Economic and Social Affairs. Sustainable Development. 2021. Available online: https:/ / sdgs.un.org/goals (accessed on 4 December 2021).

36. Bourdieu, P. The Forms of Capital. Chapter 1. pp. 15-29. Available online: https://home.iitk.ac.in/ \{\}amman/soc748/bourdieu_ forms_of_capital.pdf (accessed on 8 December 2021).

37. Sileyew, K.J. Research Design and Methodology. Chapter 3. In Cybespace; Abu-Taieh, E., Al Hadid, I.H., El Mouatasim, A., Eds.; Intech Open Book Series; Intechopen: London, UK, 2019. Available online: https:/ / www.semanticscholar.org/paper/ResearchDesign-and-Methodology-Sileyew /93ca386a87f250be07b5f776c20cd5f92751df76\#paper-header (accessed on 10 January 2022).

38. Ireland, R.D.; Hitt, M.A. Mission statements: Importance, challenge, and recommendations for development. Bus. Horiz. 1992, 35, 34-42. [CrossRef]

39. Kleinheksel, A.J.; Rockich-Winston, N.; Tawfik, H.; Wyatt, T.R. Demystifying content analysis. Am. J. Pharm. Educ. 2020, 84, 7113. [CrossRef] [PubMed]

40. Kondracki, N.L.; Wellman, N.S.; Amundson, D.R. Content analysis: Review of methods and their applications in nutrition education. J. Nutr. Educ. Behav. 2002, 34, 224-230. [CrossRef]

41. Abeysekera, I. Intellectual Capital Accounting; Routledge: New York, NY, USA, 2007; pp. 47-93.

42. Lombard, M.; Snyder-Duch, J.; Bracken, C.C. Content analysis in mass communication research: An assessment and reporting of intercoder reliability. Hum. Commun. Res. 2002, 28, 587-604. [CrossRef]

43. Krippendorff, K. Reliability in content analysis: Some common misconceptions and recommendations. Hum. Commun. Res. 2004, 30, 411-433. [CrossRef]

44. Goldbeck, J. Analysing the Social Web; Elsevier: Waltham, MA, USA, 2013.

45. Yap, M.L.-M.; Watene, K. The Sustainable Development Goals (SDGs) and Indigenous Peoples: Another Missed Opportunity? J. Hum. Dev. Capab. 2019, 20, 451-467. [CrossRef]

46. Harris, R. 'Not Our Policy': Scott Morrison Rejects Push for Referendum on Voice. 18 March 2021. Available online: https://www. smh.com.au/politics/federal/not-our-policy-scott-morrison-rejects-push-for-referendum-on-voice-20210318-p57bxc.html (accessed on 10 January 2022).

47. Statistica. Average Rainfall in Australia in 2020, by State (in Millimetres). Available online: https://www.statista.com/statistics / 610486/australia-rainfall-by-state/ (accessed on 5 December 2021).

48. Gardiner-Garden, J. Closing the Gap. Parliament of Australia. Available online: https://www.aph.gov.au/About_Parliament/ Parliamentary_Departments/Parliamentary_Library/pubs/BriefingBook44p/ClosingGap (accessed on 5 December 2021).

49. Australian Institute of Health and Welfare. Family, Domestic, and Sexual Violence in Australia: Continuing the National Story. 2019. Available online: https:/ / www.aihw.gov.au/getmedia/b0037b2d-a651-4abf-9f7b-00a85e3de528/aihw-fdv3-FDSV-inAustralia-2019.pdf.aspx?inline=true (accessed on 5 December 2021).

50. Australian Government. Australian Institute of Health and Welfare. Alcohol, Tobacco \& Other Drugs in Australia. 2021. Available online: https:/ / www.aihw.gov.au/reports/alcohol/alcohol-tobacco-other-drugs-australia/contents/priority-populations / aboriginal-and-torres-strait-islander-people (accessed on 10 January 2022).

51. Haughton, J. Indigenous Affairs Overview. Budget Review 2019-20 Index. Indigenous Budget Drivers. Parliament of Australia. 2021. Available online: https://www.aph.gov.au/About_Parliament/Parliamentary_Departments/Parliamentary_Library/ pubs/rp/BudgetReview201920/IndigenousAffairs (accessed on 11 January 2022). 